\title{
Modernizing Biomedical Training: Replacing Live Animal Laboratories with Human Simulation
}

\author{
John Pawlowski \\ Assistant Professor of Anesthesia, Department of Anesthesia, Critical Care, \\ and Pain Medicine, Beth Israel Deaconess Medical Center, MA, United States
}

\section{David Feinstein}

Assistant Professor of Anesthesia, Department of Anesthesia, Critical Care, and Pain Medicine, Beth Israel Deaconess Medical Center, MA, United States

\author{
Marie L. Crandall \\ Professor of Surgery, College of Medicine, University of Florida, Jacksonville, \\ United States
}

\section{Shalin Gala}

Vice President, International Laboratory Methods, Laboratory Investigations Department, People for the Ethical Treatment of Animals (PETA), Virginia, United States ShalinG@peta.org

\section{Introduction}

Hands-on skills training in biomedical education has traditionally relied on the use of more than 9 million live vertebrate animals each year in the United States (Us) alone (Patronek and Rauch, 2007), and more in other countries around the world, ranging from performing minor surgical manipulations and pharmacological interventions to managing major traumatic gunshot wounds, burn injuries, and dismemberments. Recently, however, a paradigm shift has taken place that has seen the full replacement of animal use in civilian medical school curricula and skills-training programs in various countries, along with significant reductions and replacements of animal use in comparable military training drills. The embrace of simulation-based biomedical training has been spurred, in part, by improvements in technological realism that accurately mimics human anatomy and physiology, financial burdens involved with running animal laboratories, heightened public awareness and ethical objections 
to the use of animals in experiments, and unique pedagogical advantages inherent in simulation-based training and assessment capabilities.

This chapter reviews the global trend towards a modernization of biomedical education in favor of simulation-based training methods, which studies confirm improve student learning and transference of applied skills to clinical practice, reduce laboratory costs, and spare animals from harmful procedures.

\section{Animals Used in Military Medical Training}

\subsection{Live Tissue Training}

The first published curtailing of the us military's use of dogs, cats, and nonhuman primates in invasive wound experiments occurred in 1983. That year, animal protection organization People for the Ethical Treatment of Animals (PETA) publicized plans by the Us Department of Defense (DOD) to shoot live dogs to create life-threatening injuries, during a so-called, "wound lab" so that military personnel could practice trauma management. Subsequently, the DOD temporarily halted all animal use for this practice before banning the use of cats, dogs, and non-human primates and allowing for the use of pigs and goats that continues today in, so-called, "live tissue training" (LTT) (Associated Press, 1984). The DOD's present-day incarnation of LTT involves creating penetrating gunshot and stab wounds, burn injuries, and limb amputations in more than 8,50o live pigs and goats each year (Klimas, 2017). Bipartisan legislation has been introduced in the us Congress (Battlefield Excellence Through Superior Training Practices Act, 2017) to replace the use of animals in LTT with superior human simulation technology, a transition supported by the New York Times Editorial Board and national physicians' organizations, among others (Johnson, 2016; Editorial Board, 2016).

Two PETA eyewitness video investigations of these military drills-one in 2012, showing live goats having their limbs cut off with tree trimmers (Kimberlin, 2012); and one in 2013, showing live pigs enduring gunshot wounds to their faces (Shiffman, 2015) - have exposed LTT to the scrutiny of the public, spurring protests and congressional inquiries (Kheel, 2016). Due in part to these developments, in 2013 the us Army required all non-medical personnel, and certain medical personnel, to use human simulation training methods exclusively, instead of LTT (Brooks, 2013). In 2014, the us Coast Guard cut its use of animals for LTT by more than half (Vergakis, 2014). In 2014, the DOD directed all military service branches to cease using animals for six areas of medical education, including Advanced Trauma Life Support training, obstetrics and gynecology residency training, pediatric intubation training, and certain types 
of trauma training among other areas (US Department of Defense, 2014). In 2017, the Us Coast Guard fully ended all use of animals for LTT in favor of human simulation models (Seck, 2017).

Internationally, a survey published in 2012 found that 22 of 28 North Atlantic Treaty Organization (NATO) nations, nearly $80 \%$ percent, do not use any animals for military medical training programs and instead use human simulation models exclusively (Gala et al., 2012). Of note, animal advocates filed complaints with German authorities about LTT permit applications by the US Army in Germany. In 2010, German officials repeatedly denied requests by the us military to proceed with this activity, concluding that the procedures would "violate host nation animal protection laws" because "effective alternatives to animals are available" (Vandiver and Kloeckner, 2010). Similarly, after animal advocates provided information to military officials about human simulators and other non-animal trauma training methods, in 2013, the Polish Ministry of National Defense ended LTT; and in 2014, the Norwegian Animal Research Authority rejected an LTT application by the Norwegian Armed Forces, since they did not provide evidence that non-animal training methods were inadequate (Baker, 2015).

\subsection{Chemical Casualty Training}

The us Army's Aberdeen Proving Ground regularly conducted training in the medical management of biological and chemical casualties by exposing as many as 48 live monkeys annually to simulated nerve agents, which can cause uncontrollable twitching, seizures, vomiting, and difficulty breathing (Vastag, 2011). The release of video footage in 2009 from this training by the Physicians Committee for Responsible Medicine (PCRM) (Lawrence, 2009)—followed by public protests, congressional inquiries, and a deluge of letters to military officials by animal advocates-led to the Army's announcement in 2011 that it would replace the use of animals with trained actors, computer programs, and high-tech human patient simulators (Vastag, 2011). In effect, the animals were replaced with more anatomically correct and physiologically relevant human models, which established a credible gravity to the educational experience (Vastag, 2011).

\subsection{Pediatric Intubation Training}

According to documents obtained by PETA via the us Freedom of Information Act from 2010 through 2014, physicians, pediatric residents, nurses, and medical technicians traditionally learned neonatal intubation by forcing hard plastic tubes down ferrets' delicate airways, as many as six times per animal each session at both Lackland Air Force Base (AFB) (2007) and Madigan 
Health System (2010); as many as five times per animal each session at both Travis AFB (2008) and Keesler AFB (2010); and as many as 10 times per animal each session at Naval Medical Center Portsmouth (Sizemore, 2012). This procedure can cause bleeding, swelling, pain, scarring, collapsed lungs, and even death. Indeed, the approved protocols at these facilities acknowledge that there is pain associated with this procedure, given that in these protocols as many as 100 animals or more were listed in the us Department of Agriculture's Column $\mathrm{D}$, which is reserved for animals experiencing pain or distress (Keesler AFB, 2010; Lackland AFB, 2007; Madigan Health System, 2010; Travis $\mathrm{AFB}, 2008)$.

Following numerous letters to the leadership of each military installation by concerned members of the public and military physicians, each facility ended its use of animals for pediatric intubation training. Per a DOD memorandum, by the year 2015, all military facilities fully transitioned to infant simulators, which are able to better represent human anatomy as well as physiological vital signs, to teach pediatric intubation skills (US DOD, 2014).

\section{Animals Used in Civilian Medical Training}

\subsection{Undergraduate Medical Curricula}

Medical students in the us have historically participated in classroom animal laboratories, such as injecting pharmaceuticals into live dogs to observe adverse side effects and performing invasive procedures on live pigs. However, a confluence of various factors, including sustained advocacy efforts by organizations such as PCRM, constricted institutional educational budgets, and the technological advancement of simulation models, helped to clear the path for the complete end of animal use in the us medical curricula in the year 2016 (Simkin et al., 2017). Canadian medical schools accomplished this feat five years earlier (Blackwell, 2011).

Perhaps one of the largest animal use policy changes in global biomedical training came from India, which for decades required medical students in Bachelor of Medicine and Bachelor of Surgery (MBBS) programs to perform pharmacology and physiology experiments on approximately 1.5 to 2 million live animals each year (Akbarsha, 2012). In part, following meetings with animal advocates, government officials, physicians, and academics, the Medical Council of India amended its MBвs regulations to replace the use of animals with non-animal training methods (DNA Correspondent, 2014). This decision that was replicated by the Pharmacy Council of India (TNN, 2014) for pharmacy training; the Dental Council of India for dental training (Singh, 2013); 
and the University Grants Commission for life science and zoology training (Pulla, 2014). These actions, now taken by many of the governing bodies of the educational systems in India, may result in saving millions of animals each year.

\subsection{Neonatal Procedure Training}

Neonatal procedural skills include the practice of infant intubation; neonatal umbilical view cannulation; neonatal chest tube insertion; and cerebrospinal fluid sampling (spinal taps). These procedures have traditionally been taught using live animals. However, the American Academy of Pediatrics (in 2005); the Emergency Nurses Association (in 2008); and the American Heart Association (in 2013) wrote to PETA to embrace the use of animal-free training methods involving human simulation. In 2011, the National Association of Neonatal Nurses (NANN) announced that they would replace their use of animals in training for these procedures with a human simulator-based curriculum, a transition facilitated by PETA, which donated newborn patient simulators (nurse.com, 2011).

At another civilian facility, Washington University in St. Louis, the Pediatric Advanced Life Support (PALS) course announced that it was replacing its use of live cats with simulation-based mannequin training. The program's decision followed complaints by PCRM and PETA's release of eyewitness video footage showing students at times struggling repeatedly to insert breathing tubes in the animals' throats (Salter, 2016).

\subsection{Advanced Trauma Life Support (ATLS) Training}

The American College of Surgeons' (ACs) Advanced Trauma Life Support (ATLS) program was introduced in 1978 and has become the standard of care for initial assessment and treatment of trauma patients. During this course, physicians historically practiced cricothyroidotomy, chest-tube insertion, pericardiocentesis, venous cutdown, and diagnostic peritoneal lavage by cutting crude holes into the chests, throats, abdomens, and limbs of live dogs, pigs, sheep and goats. In 2001, the ACS approved the use of human cadavers and the TraumaMan system (Simulab Corporation, 2017), as full replacements to the use of animals during the surgical laboratory session of the ATLS course (ACS, 2001). The TraumaMan system allows ATLS programs to avoid animal use by allowing students to practice surgical procedures on an anatomically-correct human torso that features lifelike skin, tissue, internal organs and bones, as well as simulated bleeding when cut into and airway response using a ventilator. Due in part to advocacy efforts by PCRM and others, and given the numerous studies confirming the efficacy of simulation-based training, today more than 
$99 \%$ of the 276 ATLS training facilities in the US (PCRM, 2018), and all of the 32 ATLS programs in Canada (Blackwell, 2011), now exclusively use TraumaMan and other ACs-approved non-animal training methods.

Starting in 2012, PETA surveyed international ATLS programs regarding their use of animals or simulators as part of the course's surgical skills laboratory. Numerous international ATLS officials from countries that use animals for this course expressed a desire to switch to non-animal simulation models, yet cited financial constraints as the primary transition barrier. To solve this issue, PETA established a successful groundbreaking program with Simulab Corporation and ATLS leaders in 22 countries to cost-effectively replace their use of animals with TraumaMan models, sparing thousands of animals from undergoing terminal surgical procedures while also improving trauma-skills training for physicians around the world (McNeil, 2014; Belisomo, 2015; People for the Ethical Treatment of Animals, 2017).

Concurrent with the advances in the use of simulation for human medical education, a surge of knowledge, curricula, and simulation technologies have been applied to the field of veterinary medicine. In addition to using simulators to teach physical diagnosis skills, these devices have been employed to teach clinical procedures (Hodgson and Pelzer, 2017). In 2010, researchers described the use of simulation-based training to teach the bovine rectal exam (Baillie et al., 2010). Simulators have been used to instruct veterinary students in procedures as well as in laparoscopic surgical techniques (Kilkenny, 2016). Industries (n.d.) has expanded to develop species-specific, whole body simulators for horses, cattle, sheep, dogs, cats, and a variety of other animals. These simulators have the advantage of species-specific physiological and pharmacological models, as well as relevant anatomical structures.

In addition to task and procedural training, veterinary simulators have been applied to teach team training and aspects of professionalism (Caraballo et al., n.d.; Scalese and Issenberg, 2005). Mossop (2012) described the teaching of certain professional traits using veterinary simulators. These traits included communication, ethical reasoning, reflective practice, and learning skills. Communication skills and professionalism are among the most common reasons for failure during clinical rotations and for the filing of malpractice suits (Hoffman, 2016).

Similar to the professional development goals articulated by the Accreditation Council for Graduate Medical Education, the American Veterinary 
Medical Association maintains a list of required standards for all graduates from accredited veterinary medical schools. These traits of integrity, teamwork, communication, and honesty can be brought out and discussed during simulated exercises. The simulation encounters can be altered to be more difficult for advanced students or repeated for students who need remediation.

In summary, the field of veterinary medicine has seen a recent expansion of animal simulators and simulation curricula to teach the practical and professional aspects of a veterinary practice. These new simulation-based developments provide humane teaching tools that allow replacement of the harmful use of live animals in veterinary science education.

\section{Non-animal Training Methods}

Numerous curricular reforms have led to a dramatic decrease in the use of live animals for biomedical training around the world. In most cases, some form of whole body simulation and/or task trainer devices are used as educational tools in place of animals. Implicit in the replacement of animal use is that the simulation-based methods have equal or better pedagogical outcomes for the learners, and several studies confirm this point (Patronek and Rauch, 2007).

\subsection{High-fidelity Simulation Accurately Models Human Patients}

Many whole body mannequins and partial task trainers can bleed, breathe, and simulate realistic surgical procedures. Examples include, Multiple Amputation Trauma Trainer simulator (Kforce Government Solutions, Inc., 2014); high-fidelity SimMan Essential simulator (Laerdal Medical, 2017); Caesar trauma patient simulator (CAE Healthcare, 2017); hyper-realistic Cut Suit model (Strategic Operations, 2015); and TraumaMan model (Simulab Corporation, 2017). Simulators can adapt to medications with changes in heart rate, blood pressure, and respiratory rate. The physiological responses are based on hemodynamic models of humans and, therefore, are well suited to teach medical students. During clinical training, medical students can practice asking questions that probe a patient's medical history, and the mannequin's response to these questions can facilitate further inquiries by the student. This way, the student can piece together essential information to compile a detailed history and differential diagnosis. Far from being limited to simple signs and sounds, whole body simulators can evoke complex cognitive issues and require synthesis, analysis, and processing of medical information to determine the various disease entities. To teach trainees to recognize different pathophysiological 
states, the mannequin can demonstrate a number of disease symptoms. For example, the mannequin can wheeze, develop a murmur, or produce muffled bowel sounds. Acute airway obstruction or tension pneumothorax can prompt an emergent clinical response from students, years before they would be ready to treat a patient with assurance.

Surgical procedures can also be taught using either virtual reality simulation or task trainers in conjunction with whole body mannequins. For example, an entire laparoscopic cholecystectomy can be performed in virtual reality, with students manipulating laparoscopic instruments in an environment that mimics the surgical anatomy, duplicates bleeding vessels, and features flaming cautery to coagulate hemorrhage. Task trainers can similarly depict abdominal structures that the student must identify and retract in order to expose and remove the gall bladder. These simulator options can also be used to measure reduction in time to perform a task as a measure of proficiency, record surgical errors, and be accompanied by real-time feedback and deliberate practice (Reznick and MacRae, 2006).

\subsection{Simulators Improve Technical Proficiency}

In a randomized study on emergency procedures, Hall (2011) assigned trainees to complete procedural tasks on human simulators or on live animal tissue models. Results demonstrated that trainees' acquisition of procedural skills were significantly better when simulators were used. Most of the perceived benefits came from the human anatomical features of the simulators. This preference for the human anatomical model was also demonstrated in a study by McCarthy et al. (2002), who compared cricothyroidotomy sessions using canine versus human cadaver models. They found that trainees performed procedures more accurately on the latter.

Simulation technologies exist for many levels and subjects in biomedical education. Early training with whole body simulators has been shown to be effective in teaching the principles of physiology to first year medical students. Tan et al. (2002) described the range of simulation-based sessions in preclinical medical school courses, which include introduction of clinical situations and diseases; elements of history taking and empathetic styles; formation of a differential diagnosis; and corroboration of physical examination findings.

\subsection{Simulators Improve Patient and Medical Provider Safety}

Medical students learning either internal medicine or general surgery can benefit from simulation-based teaching. All simulation training avoids the potential risks to the patient of medical trainee-induced complications (Friedrich, 2002). For example, the first needle insertion, suture repair, or incision by a 
medical student can be done using a simulator. A hallmark of simulation allows students to perform numerous medical procedures and receive satisfactory assessment by skilled instructors, before any attempts on a live human patient, thereby minimizing patient injury and complications during the period of early training. In addition, the use of simulation can prove to be safer for the medical student. Needle punctures can result in the transmission of disease, such as hepatitis or HIV. Therefore, avoidance of early needle punctures for infected patients using simulators, allows students to gain some proficiency and avoid the risk of self-inflicted needle injury with a contaminated needle. For both the patient and the student, early use of simulators can provide important safety benefits.

\subsection{Simulators Foster Development of Higher-Order Cognitive Skills}

Simulation-based training can also teach a host of higher-order cognitive lessons. In 2006, Takayesu and colleagues examined the use of high-fidelity patient simulation in medical student learning. Participants were asked to report on their experience following a simulation-based clinical exercise. Aside from the simulators' "learning by doing" paradigm that fosters technical skills development, 46 percent of the students felt that simulators are superior to other methods in teaching "clinical decision making" and "communication and teamwork". These subjects are considered more conceptual and complex and require higher-order cognitive skills; and they are often associated with essential elements of professionalism. The authors concluded that simulation exercises help students to integrate pathophysiological concepts into clinical situations in a risk-free environment (Takayesu et al., 2006).

\subsection{Students Benefit from Immersive Simulation-Based Training that Mimics Realistic Clinical Scenarios}

Not only do simulators allow for a fairly realistic depiction of anatomic structures, but they can also allow students to be immersed in a realistic environment that resembles an operating room. Surgical equipment, anesthesia machines, gowns, and gloves can bring the learner into an engaging and realistic clinical space. The level of engagement simulation offers has been well-described, and such levels of activation are crucial to learning (Oriol et al., 2011). In surgical literature, Kaufman (2003) described how simulation not only allows for deliberate technical practice but can also be integrated into the clinical environment. Kaufman described the use of simulation to teach and coordinate the care of military patients in a multi-casualty setting; however, the lessons learned can likely apply to civilian circumstances. All surgical operations involve teams and communication. All surgical procedures have 
periods of technical challenge, and other times may include logistical problems. Simulation-based training can provide a realistic situation of urgency, emotional stress, and technical demand that require quick decisions, precise actions, and coordinated follow-up. With trained clinical raters, the participants can receive valuable feedback about their decision making, technical surgical skill proficiency, teamwork, and communication. It is important to note that only a small portion of medical learning objectives involve task completion. Indeed, most of the skills are non-technical and include effective communication, an organized approach, management of resources and people, and maintenance of global awareness. The conversion from animal-based training to the use of simulators allows for a preservation of effective learning and an increase in patient safety (Balcombe, 2004).

\subsection{Simulation Shortens Medical Trainees' Learning Curve}

Issenberg et al. (2005) systematically reviewed the best clinical evidence for the use of simulation in medical education and found that the majority of studies demonstrate the utility of simulation in providing faster learning with better retention of concepts over time. Almost all of the reviewed papers showed that simulation was as least as good as, if not better than, conventional teaching methods. Another study showed that simulation-based training accelerated or shortened the learning curve that any novice or trainee experiences by allowing for ongoing coaching, evaluation, feedback, and correction through deliberate practice (Patel, et al., 2006). In both civilian medicine and military medical training, the use of simulation has become a key component of the curriculum (Hauck, 2016).

There is a global lack of policy harmonization between countries and locally between laboratories, regarding the use of animals in biomedical education. For example, the United Kingdom prohibits surgical training on live animals, yet other countries still allow the use of animals for this purpose. The Us Army has banned the use of animals in trauma training drills by non-medical personnel, yet other us military service branches continue to allow non-medical personnel to use animals in these exercises. Twenty-two NATO nations, including 19 European Union (EU) Member States, have confirmed that they do not use any animals for military medical training (Gala et al., 2012). Yet, six NATO nations continue to use animals for LTT, some of which are EU countries bound by Directive 2010/63/EU (European Parliament, 2010) that requires the 
use of non-animal training methods whenever available. Also, many medical schools around the world continue to use animals in physiology and pharmacology training, among other disciplines, even though this practice has been abandoned by all medical schools in the us, Canada, and India.

Efforts should be made to identify procedures, skills, or concepts that are currently taught at certain facilities using simulation technology and advocate for their adoption by comparable training programs still using animals for these lessons. Numerous countries mandate that animal use in biomedical training be justified to obtain animal ethics committee approval. However, when similar procedures, skills, or concepts are taught in one facility with simulation models and at another facility using animals, the latter may encounter difficulty in justifying its use of animals upon scrutiny. Times are changing, with more and more training facilities taking up non-animal methods for the training of their students. In time, it will become more difficult for other training institutions to continue to justify their use of animals in biomedical training, resulting in a new generation of medically trained professionals, who are distanced from the antiquated use of animals in education.

\section{$7 \quad$ Conclusion}

The modernization of biomedical education has gone hand-in-hand with an embrace of advanced human simulation technology and a reduction in the use of animals for training. Just as a century ago, the decline in the number of buggy whips produced could portend the acceptance of the automobile, the world-wide decline in the use of live animals used in medical training can provide evidence for the value of simulation training in science and medicine.

\section{References}

Akbarsha, M.A. (2012). Alternatives Session at Medical Students' Forum. Alternatives to Animal Experimentation, 29(3).

Associated Press (1984). Reprieve from Wound Tests Is Ended for Pigs and Goats. New York Times, [online] Available at: http://www.nytimes.com/1984/o1/24/us/reprieve -from-wound-tests-is-ended-for-pigs-and-goats.html [Accessed 1o May 2017].

Baillie, S., A. Crossan, S.A. Brewster, S.A. May and D.J. Mellor (2010). Evaluating an Automated Haptic Simulator Designed for Veterinary Students to Learn Bovine Rectal Palpation. Simulation in Healthcare: The Journal of the Society for Simulation in Healthcare, 5(5), pp. 261-266. 
Baker, B. (2015). Putting an End to Cruel "Danish bacon" Animal Wounding Exercises. Army Technology, [online] Available at: http://www.army-technology.com/featu res/featureputting-an-end-to-cruel-danish-bacon-animal-wounding-exercises $-4505465 /$ [Accessed 10 May 2017].

Balcombe, J. (2004). Medical Training Using Simulation: Toward Fewer Animals and Safer Patients. Alternatives to Laboratory Animals, 32(1), pp. 553-560.

Battlefield Excellence Through Superior Training Practices Act 2017. Washington, D.C.: 115th Congress House Bill. [online] Available at: https://www.congress.gov/bill/115th -congress/house-bill/1243/text [Accessed 10 May 2017].

Belisomo, R. (2015). "Traumaman" Helps Doctors Save Humans, Spares Animals. Reuters. [online]. Available at: http://www.reuters.com/article/us-health-surgeons -traumaman-idUSKCNoRP1O620150925 [Accessed 23 June 2017].

Blackwell, T. (2011). Canadian Med Schools End Use of Live Animals. National Post. [online]. Available at: http://nationalpost.com/news/canada/canadian-med-schools -end-use-of-live-animals/wcm/b9676995-55d9-459e-bf87-53185368b175 [Accessed 10 May 2017].

Brooks, D. (2013). Activists: Army to Limit Live Animal Training. Military.com. [online]. Available at: http://www.military.com/daily-news/2013/04/02/activists-army-to -limit-live-animal-training.html [Accessed 10 May 2017].

CAE Healthcare (2017). CAE Caesar Trauma Patient Simulator. [online] Available at: https://caehealthcare.com/patient-simulation/caesar [Accessed 1o May 2017].

Caraballo, M., Duenas, J.L.P., Tellez, E.I. and Fraga-Sastrias, J.M. (n.d.). The use of a high fidelity simulator for veterinary medicine training. Laerdal Mexico. [online] Available at: https://pdfs.semanticscholar.org/12aa/f6g6bbbcf439dbo8ed837135a76f812c68gf. pdf [Accessed 11 October 2018].

DNA Correspondent (2014). Medical Council of India Stops Use of Animals for Training U G Medical Students. Daily News \& Analysis. [online] Available at: http://www .dnaindia.com/mumbai/report-medical-council-of-india-stops-use-of-animals-for -training-ug-medical-students-1981373 [Accessed 10 May 2017].

European Parliament (2010). Directive 2010/63/EU of the European Parliament and of the Council of 22 September 2010 on the protection of animals used for scientific purposes. OfficialJournal of the European Communities, L276, p. 33-79. [online] Available at: http://eur-lex.europa.eu/legal-content/EN/TXT/?uri=CELEX\%3A32010Loo63 [Accessed 12 August 2017].

Friedrich, M.J. (2002). Practice Makes Perfect: Risk-free Medical Training with Patient Simulators. Journal of the American Medical Association, 288(22), pp. 2808.

Gala, S., J. Goodman, M. Murphy and M. Balsam (2012). Use of Animals by NATO Countries in Military Medical Training Exercises: An International Survey. Military Medicine, 177(8), pp. 907-910. [online] Available at: https://www.ncbi.nlm.nih.gov/ pubmed/22934368 [Accessed 10 May 2017]. 
Hall, A.B. (2011). Randomized Objective Comparison of Live Tissue Training Versus Simulators for Emergency Procedures. The American Surgeon, 77(5), pp. 561-565.

Hauck, S. (2016). Simulators, Manikins, Key Part of Military Medical Training. The Daily News. [online] Available at: http://www.jdnews.com/news/20161228/simulators -manikins-key-part-of-military-medical-training [Accessed 10 May 2017].

Hodgson, J.L. and J.M. Pelzer (2017). Veterinary medical education: A practical guide. Hoboken: Wiley-Blackwell.

Hoffman, J. (2016). Malpractice risks in communication failures. Crico. [online] Available at: https://www.rmf.harvard.edu/Clinician-Resources/Newsletter-and-Publi cation/2016/SPS-The-Malpractice-Risks-of-Health-Care-Communication-Failures [Accessed 10 May 2017].

Issenberg, B.S., W.C. McGaghie, E.R. Petrusa, D.L. Gordon and R.J. Scalese (2005). Features and Uses of High-fidelity Medical Simulations That Lead to Effective Learning: A BEME Systematic Review. Medical Teacher, 27(1), pp. 10-28.

Johnson, H. (2016). Leading Medical Groups Endorse Johnson's Military Modernization Bill. Press Release. Representative Hank Johnson, us House of Representatives. [online] Available at: https://hankjohnson.house.gov/media-center/press-releases/ leading-medical-groups-endorse-johnson-s-military-modernization-bill [Accessed 10 May 2017].

Kaufmann, C.R. (2003). Surgical Simulation: A Clinical Perspective. Military Medicine, 168(9), pp. 16-20.

Keesler Air Force Base (2010). Endotracheal Intubation Training Exercise Using a Ferret Model (Mustela Putorius Furo). Protocol No. FKE20100032A.

Kforce Government Solutions, Inc. (2014). Multiple Amputation Trauma Trainer (MATT) Series 1500 Trauma Trainer. [online] Available at: https://www.kforcegov .com/TraumaFX/TraumaFX_Files/KGS\%2oTraumaFX\%20MATT.pdf [Accessed 10 May 2017].

Kheel, R. (2016). Lawmakers Press Pentagon to Stop Using Animals in Medical Training. The Hill. [online] Available at: http://thehill.com/policy/defense/284262-lawmakers -press-pentagon-on-animal-use-in-medical-training [Accessed 10 May 2017].

Kilkenny, J. (2016). Investigation of Laparoscopic Skills in Veterinary Students Using Simulation Technology. The Atrium. [online] Available at: https://atrium.lib .uoguelph.ca/xmlui/bitstream/handle/10214/9581/kilkenny_jessica_201603_MSc .pdf? sequence $=\mathbf{1}$ [Accessed 10 May 2017].

Kimberlin, J. (2012). Military Contractor Cited for Treatment of Goats. VirginianPilot. [online] Available at: https://pilotonline.com/news/military/local/military -contractor-cited-for-treatment-of-goats/article_3aaeof87-114a-5d29-8cb7-d8dba ooceed8.html [Accessed 1o May 2017].

Klimas, J. (2017). The Military Kills 8,500 Pigs and Goats Every Year for Medical Training. A New Bill Would End That. Washington Examiner. [online] Available at: 
http://www.washingtonexaminer.com/the-military-kills-8500-pigs-and-goats -every-year-for-medical-training-a-new-bill-would-end-that/article/2616416 [Accessed 10 May 2017].

Lackland Air Force Base. (2007). Intubation Instruction and Training Utilizing a Ferret (Mustela Putorius) Model. Protocol No. FWH20090154A.

Laerdal Medical (2017). SimMan ${ }^{\circledR}$ Essential. [online] Available at: http://www.laerdal .com/us/products/simulation-training/emergency-care-trauma/simman-essen tial/ [Accessed 10 May 2017].

Lawrence, C. (2009). Videos Renew Debate on Military Use of Animals. Cable News Network $(C N N)$. [online] Available at: http://www.cnn.com/2009/POLITICS/06/05/ military.animals.training/index.html?iref=24hours [Accessed 10 May 2017].

Madigan Health System (2010). Pediatric Intubation Training Utilizing the Ferret (Mustela Putorius Furo) Model. Protocol Nos. 204028 and 210043.

McCarthy, M.C., M.R. Ranzinger, D.J. Nolan, C.S. Lambert and M.H. Castillo (2002). Accuracy of Cricothyroidotomy Performed in Canine and Human Cadaver Models During Surgical Skills Training. Journal of the American College of Surgeons, 195(5), pp. 627-629.

McNeil, D.G. Jr. (2014). PETA's donation to Help Save Lives, Animal and Human. The New York Times. [online] Available at: https://www.nytimes.com/2014/o1/14/health/ petas-donation-to-help-save-lives-animal-and-human.html [Accessed 21 June 2017].

Mossop, L. (2012) Defining and Teaching Veterinary Professionalism. PhD. The University of Nottingham [online] Available at: http://eprints.nottingham.ac.uk/12694/1/ Fully_corrected_thesis_Liz_Mossop.pdf [Accessed 3 May 2017].

Nurse.com (2011). PETA Donates Infant Simulators to National Association of Neonatal Nurses. [Blog] Available at: https://www.nurse.com/blog/2011/10/10/peta-donates -infant-simulators-to-national-association-of-neonatal-nurses/ [Accessed 10 May 2017].

Oriol, N.E., E.M. Hayden, J. Joyal-Mowschenson, S. Muret-Wagstaff, R. Faux and J.A. Gordon (2011). Using Immersive Healthcare Simulation for Physiology Education: Initial Experience in High School, College, and Graduate School Curricula. Advances in Physiology Education, 35(3), pp. 252-219.

Patel, A.D., A.G. Gallagher, W.J. Nicholson and C.U. Cates (2006). Learning Curves and Reliability Measures for Virtual Reality Simulation in the Performance Assessment of Carotid Angiography. Journal of the American College of Cardiology, 47(9), pp.1796-1802.

Patronek, G.J. and A. Rauch (2007). Systematic review of comparative studies examining alternatives to the harmful use of animals in biomedical education. Journal of the American Veterinary Medical Association, 230(1), pp. 37-43.

People for the Ethical Treatment of Animals (PETA) (2017). PETA donates Surgical Simulators, Saving More Animals' Lives. [online] Available at: https://www.peta 
.org/blog/peta-donates-more-traumaman-surgical-simulators/ [Accessed 23 June 2017].

Physicians Committee for Responsible Medicine (2018). Survey of ATLS programs. [online] Available at: http://www.pcrm.org/research/edtraining/ATLS/survey-of-atls -programs [Accessed 11 October 2018].

Pulla, P. (2014). Dissections Banned in Indian Universities. Science. [online] Available at: http://www.sciencemag.org/news/2014/o8/dissections-banned-indian-universities [Accessed 13 Mar. 2017].

Reznick, R.K. and H. MacRae (2006). Teaching Surgical Skills-Changes in the Wind. New England Journal of Medicine, 355(25), pp. 2664-2669.

Salter, J. (2016). Washington University Stops Intubation Training Using Cats. Associated Press News. [online] Available at: https://apnews.com/o64e58c1018f464ca $4 \mathrm{cc} 4$ be2b429913o/washington-university-stops-intubation-training-using-cats [Accessed 10 May 2017].

Scalese, R.J. and S.B. Issenberg (2005). Effective Use of Simulations for the Teaching and Acquisition of Veterinary Professional and Clinical Skills. Journal of Veterinary Medical Education, 32(4), pp. 461-467.

Seck, H.H. (2017). Ending "Abhorrent" Live Tissue Training Was Right: Coast Guard. Military.com. [online] Available at: https://www.military.com/daily-news/2017/05/ 18/ending-abhorrent-live-tissue-training-was-right-coast-guard.html [Accessed 14 February 2018].

Shiffman, J. (2015). Exclusive: Doctor Who Trained us Troops Suspended for Macabre Techniques. Reuters. [online] Available at: http://www.reuters.com/article/us-usa -doctor-probe-idUSKBNoOO2E7201506o8 [Accessed 1o May 2017].

Simkin, D.J., J. Greene, J. Jung, B. Sacks and H. Fessler (2017). The Death of Animals in Medical School. New England Journal of Medicine, 376(8), pp. 713-715.

Simulab Corporation (2017). Surgical Trainer for Chest Tube Insertion, Cricothyroidomy (or Cricothyrotomy), Needle Decompression, Tracheostomy, Pericardiocentesis, and Diagnostic Peritoneal Lavage. [online] Available at: https://www.simulab.com/ traumaman/about [Accessed 1o May 2017].

Singh, V. (2013). Dental Council Bans Use of Animals in Training. The Times of India. [online] Available at: http://timesofindia.indiatimes.com/city/mumbai/Dental -Council-bans-use-of-animals-in-training/articleshow/19110677.cms [Accessed 13 Mar. 2017].

Sizemore, B. (2012). Portsmouth Naval Medical Center To End Ferret Use. VirginianPilot. [online] Available at: https://pilotonline.com/news/military/portsmouth -naval-medical-center-to-end-ferret-use/article_2egcif76-8564-566f-a6d7-24 cfc8o881ee.html [Accessed 10 May 2017].

Strategic Operations (2015). Surgical Cut Suit. Strategic Operations. [online] Available at: http://www.strategic-operations.com/product/surgical-cut-suit/ [Accessed 10 May 2017]. 
Takayesu, J.K., S.E. Farrell, A.J. Evans, J.E. Sullivan, J.B. Pawlowski and J.A. Gordon (2006). How Do Clinical Clerkship Students Experience Simulator-based Teaching? A Qualitative Analysis. Simulation in Healthcare: The Journal of the Society for Simulation in Healthcare, 1(4), pp. 215-219.

Tan, G.M., L.K. Ti, S. Suresh, B.S. Ho and T.L. Lee (2002). Teaching First-year medical Students Physiology: Does the Human Patient Simulator Allow for More Effective Teaching?. Singapore Medical Journal, 43(5), pp. 238-242.

The Editorial Board (2016). Ban Animal Use in Military Medical Training. New York Times. [online] Available at: https://www.nytimes.com/2016/06/26/opinion/ ban-animal-use-in-military-medical-training.html [Accessed 1o May 2017].

TNN (2014). Pharmacy Students Banned from Dissecting Animals. The Times of India. [online] Available at:http://timesofindia.indiatimes.com/city/bengaluru/Pharmacy -students-banned-from-dissecting-animals/articleshow/41722224.cms [Accessed 10 May 2017].

Travis Air Force Base (2008). Neonatal Resuscitation Training Using the Domestic Ferret, Mustela Putorius Furo. Protocol No. FDG20080031A.

us Department of Defense (2014). Determination for the Use of Animals in Medical Education and Training. The Journal of Special Operations Medicine. [online] Available at: https://www.jsomonline.org/TCCCEsp/o6\%2oTCCC\%2o Documentos \%2ode\%2oReferencia/ASDHA\%2oMemo\%20140515\%2oLTT\%2oPolicy.pdf [Accessed: 13 Mar. 2017].

Vandiver, J. and M. Kloeckner (2010). German Ruling Puts USAREUR Plans for Liveanimal Medical Training on Hold. Stars and Stripes. [online] Available at: https:// www.stripes.com/news/german-ruling-puts-usareur-plans-for-live-animal-medical -training-on-hold-1.114989 [Accessed 10 May 2017].

Vastag, B. (2011). Army to Phase Out Use of Animal Nerve-agent Testing. Washington Post. [online] Available at: https:/www.washingtonpost.com/national/health -science/army-agrees-to-phase-out-use-of-animal-nerve-gas-testing/2011/10/13/ gIQAip1PiL_story.html?utm_term=.d6b32c8ogdd3 [Accessed 10 May 2017].

Vergakis, B. (2014). Coast Guard Reduces Use of Live Animal Training. Boston Globe. [online] Available at: https://www.bostonglobe.com/news/nation/2014/02/14/coast -guard-reduces-use-live-animal-training/hT16xG4Ij9IDxr26TSoRgL/story. html [Accessed 10 May 2017].

Veterinary Simulator Industries (n.d.). Products. [online] Available at: http://vetsimu lators.com [Accessed 3 May 2017]. 